\title{
Cosmopolitanism and the Mediating Effect of Country Image on Consumers' Purchase, Visit and Investment Intentions
}

\author{
Ana SOUSA ${ }^{1}$, Helena NOBRE ${ }^{2}$, Minoo FARHANGMEHR ${ }^{3}$ \\ Received: July 08, 2019 Revised: September 16, 2019 Accepted: September 30, 2019
}

\begin{abstract}
The paper aims to understand the mediating effect of Country Image (CI) on the relationship between consumer cosmopolitanism and consumers' purchase, visit and investment intentions towards a foreign country, considering the moderating effects of ethnocentrism, materialism, product familiarity, and visits to a country in a global market. The study extends research on the global and local consumption by simultaneously analysing the influence of country image dimensions and several moderating effects on consumers' behavioural intentions. Four hundred and fifty-seven valid responses from international consumers were collected through a questionnaire measuring country image dimensions. Findings indicate that cosmopolitanism has a significant and positive effect on foreign consumers' behavioural intentions and country image dimensions mediate this relationship. Moreover, a moderating effect was found for ethnocentrism, materialism, product familiarity, and visits to a country on the relationship between country cognitions and the intentions to visit the country. This study shows the importance of considering cosmopolitanism as a potential segmentation variable in international markets. The results can help managers and policymakers to better understand the image that foreign consumers hold about Portugal, their intentions to buy or invest in the country, as well as to think of Portugal as a tourism destination.
\end{abstract}

Keywords : Country Image, Cosmopolitanism, Consumer Ethnocentrism, Materialism, International marketing

JEL Classification Code : M300, M310, M390

\section{Introduction}

The strategic management of country image should take into account the strengthening of a country's position in the global market, through the identification of the environmental forces that may affect marketability, as well as monitoring the external environment, leading to the

1 First Author and Corresponding Author, PhD Researcher, School of Economics and Management (EEG), University of Minho, GOVCOPP, University of Aveiro, Portugal. [Postal Address: Rua de Júlio Dinis, n.ำ 108, Hab. 33, 4050-318 Porto, Portugal] Email: ferreira.antunes.ana@gmail.com

2 Assistant Professor, DEGEIT - Economics, Management, Industrial Engineering and Tourism, GOVCOPP, University of Aveiro, Portugal. Email: hnobre2@gmail.com

3. Professor, School of Economics and Management (EEG), University of Minho, Braga, Portugal. Email: minoo@eeg.uminho.pt

(c) Copyright: Korean Distribution Science Association (KODISA) This is an Open Access article distributed under the terms of the Creative Commons Attribution Non-Commercial License (http://Creativecommons.org/licenses/by-nc/4.0/) which permits unrestricted noncommercial use, distribution, and reproduction in any medium, provided the original work is properly cited. acquisition of a dynamic understanding of opportunities and threats beyond the competitive forces (Kotler \& Gertner, 2002). One possible way to conceptualise the Country Image (CI) it is as a knowledge structure that differs in its uniqueness, favourability, strength and salience, which means that the number of associations as well as the number of links between the associations, will differ between country images. It is important to refer that strong knowledge structures will have a positive impact on consumers' attitudes particularly in what concerns the transferability of country equity, defined as "that portion of consumer affect toward a brand or product that is derived purely from the product's associations with a particular country", across product categories, being positively affected by how multifaceted a country image is (Kleppe, Iversen, \& Stensaker, 2002, p. 62). One of the marketer's challenge is to understand which attributes and specific images consumers associate to a selected country and how they respond to different marketing strategies. This knowledge will support destiny managers and policymakers decisions to promote a distinctive country image message. 
White, Kiousis, Buhmann, and Ingenhoff (2019) define $\mathrm{CI}$ as "the perception about a country based on a number of individual assessments, some of which are rational and cognitive, some of which are based on affective and emotional processes" (p. 294). The emphasis in communicating the CI should be on what the country means to the consumer, specifically in understanding their feelings and attitudes (Hankinson, 2001). This constitutes a real challenge, since the creation of added value for "place customers" requires an effective branding to make the place "visible" in a compatible way, which means creating favourable country associations in consumers' minds (Killingbeck \& Trueman, 2002).

This investigation aims to understand the mediating effect of country image dimensions on the relationship between consumer cosmopolitanism and consumers' purchase, visit and investment intentions, considering the moderating effects of consumer ethnocentrism, materialism, product familiarity, and visits to a country in a Portuguese context, that is, Portuguese products and tourism. This study is based on the perceptions of 457 foreign consumers, mostly from Brazil, Germany, Italy and Spain. To the best of our knowledge, explicit analysis considering the mediating effect of country cognitions and country affect on the relationship between consumer cosmopolitanism and consumers' behavioural intentions and the moderating effects have not been conducted. Moreover, previous research on country image has focused on the differences between countries. This study rather assesses a common country image within foreign consumers, and offers a new perspective about the influence of country image dimensions and selected moderating effects on foreign consumers' purchasing, visiting and investment intentions.

The following research questions are investigated: (1) What is the mediating effect of Country Image on the relationship between consumer cosmopolitanism and consumers' purchase (PI), visit (VI) and investment (II) intentions?, and (2) How the effect of the moderating variables consumer ethnocentrism, materialism, country product familiarity and visits to a country, influence the relationship between CI dimensions and consumers' PI, VI and II towards a foreign country?

To address these questions, we developed and tested a conceptual model where cosmopolitanism influence country cognitions and country affect, which in turn positively influence consumer's purchase, visit and investment intentions. Specifically, we propose that country image dimensions mediate the relationship between consumer cosmopolitanism and consumer behavioural intentions. Moreover, we also analyse the moderator effects on the relation between the $\mathrm{CI}$ dimensions and the outcome variables.

\section{Conceptual Background}

\subsection{Consumers' Positive Disposition toward Foreign Countries}

According to Anderson (1998, p. 267) cosmopolitanism is understood as a flexible term which "endorses reflective distance from one's cultural affiliations, a broad understanding of other cultures and customs, and a belief in universal humanity" and has been considered by some authors (Cannon \& Yaprak, 2002; Cleveland \& Laroche, 2007; Riefler, Diamantopoulos, \& Siguaw, 2012; Saran \& Kalliny, 2012) as an interesting base for consumers' international segmentation for companies seeking international grow by going global. Cannon and Yaprak (2002, p. 30) suggest that the concept of cosmopolitan consumer refers to a "world citizen" - a consumer whose orientation transcends any particular culture or setting", which means that a cosmopolitan consumer is willing to experience tourism, living and working abroad, suggesting that a cosmopolitan orientation takes place when people regard the world as their market place and are willing to consume products, places and experiences originating from other cultures.

Riefler and Diamantopoulos (2009) describe a cosmopolitan consumer as "an open-minded individual whose consumption orientation transcends any particular culture, locality or community and who appreciates diversity including trying products and services from a variety of countries" (p. 415). In 2012, Riefler, Diamantopoulos, and Siguaw based on this conceptualisation of consumer cosmopolitanism and the contributions of other authors (Alden, Steenkamp, \& Batra, 2006; Cleveland \& Laroche, 2007; Riefler \& Diamantopoulos, 2009), developed the CCOSMO scale composed by the following dimensions: (1) Open-mindedness has its roots in one of the Big Five personality traits namely openness to experience, and might described as an "unprejudiced disposition towards other countries and cultures as expressed in an interest in experiencing their authentic manifestations" (Riefler et al., 2012, p. 287); (2) Diversity appreciation is characterised as a real appreciation about the differences and diversity in the world, which means an individual who values cultural diversity instead of uniformity, pursuits contrasts and appreciates the availability of products from diverse cultures (Caldwell, Blackwell, \& Tulloch, 2006; Hannerz, 1990). Riefler et al. (2012, p. 288) define diversity appreciation as "a positive disposition towards the diversity offered by the availability of goods and services from different national or cultural origins"; and (3) Consumption transcending borders is defined as "a positive disposition towards consuming goods and services from foreign countries" (Riefler et al., 2012, p. 288), based on the positive attitude that cosmopolitan consumers show on consuming products from other cultures in order to experience them. The use of this scale allows to identify cosmopolitan consumers on 
consumption-relevant characteristics and provides information into their consumption tendencies.

As highlighted by Cleveland, Laroche, Takahashi, and Erdoğan (2014), the investigation about consumers' positive dispositions towards foreign countries is an important topic of research that needs further investigation. Hence the following hypothesis has been formulated:

H1: Consumer cosmopolitanism has a positive influence on consumers' intentions to (a) purchase, (b) visit, and (c) invest in a foreign country.

\subsection{The Mediating Roles of Country Cognitions and Country Affect}

Fetscherin (2010) suggests that a solid and unique country image promotes differentiation on the world stage attracting tourism, stimulating business and economic performance, and creates positive impressions and attitudes in the target markets. The concept of image has been a topic of great interest in several disciplines such as consumer behaviour, marketing, and psychology (Barich \& Kotler, 1991). The authors describe image has been the sum of beliefs, attitudes, and impressions that an individual or a group form on an object. This object can assume different forms such as a product, brand, company, person or a country. It is important to analyse what kind of impressions (true or false, real or imagined) consumers establish with countries and their products (Papadopoulos, 1993).

Considering the focus of this study, the objective was to evaluate the global image that consumers have of a country. This means that CI is formed not only by cognitive beliefs (e.g., representative products, the level of economic and political development, the degree of innovation and technological progress) but also by an affective component responsible for capturing the emotions and feelings of a particular country (Roth \& Diamantopoulos, 2009). As Carneiro and Faria (2016) suggested according to the literature review three general levels of abstraction have been identified considering the delimitation of the country image domain. This study focus on the CI domain, referring to general aspects/facets of the country, irrespective of any specific product category or any particular product. The objective is to analyse a macro country image. In the review carried out by Roth and Diamantopoulos (2009) concerning the country image construct, it seems to be a lack of clarity regarding its conceptual specifications and CI has been defined in several ways such as "perceptions" (e.g., Allred, Chakraborty, \& Miller, 2000; Min Han, 1989; Nebenzahl, Jaffe, \& Usunier, 2003), "impressions", "associations", "stereotypes" (e.g., Askegaard \& Ger, 1998) and, finally, "beliefs" (e.g., Martin \& Eroglu, 1993).

A closer look at the definitions discloses that each one, considered individually, does not fulfil the domain of the country image construct. Within country-of-origin context attitude theory seems to be the only concept that overcomes these limitations and predicts simultaneously, cognitive, affective and connotative aspects. Attitudes are defined as "a learned predisposition to respond in a consistently favourable or unfavourable manner with respect to a given object" (Fishbein \& Ajzen, 1975, p. 6), which enables to describe the positive or negative consumer's country evaluations.

As Zeugner-Roth and Žabkar (2015) suggested the relative influence of country cognitions and country affect on consumer behaviour differ, and findings from CI studies are highly important since they provide strategic information to firms that cross borders by "exporting their products, manufacturing abroad, and/or competing in their home markets against foreign companies" (Laroche, Papadopoulos, Heslop, \& Mourali, 2005, p. 97). Therefore, CI research is becoming more significant and prominent due to the increasing trend of free trade and the rapid globalisation of national economies.

This study aims to provide further knowledge about the mediating role of CI dimensions on the relationship between consumers' cosmopolitanism and their purchase, visit and investment intentions. The hypotheses of the study are inferred as follows:

H2: Country Image has a mediating effect on the relationship between consumer cosmopolitanism and consumers' intentions to (a) purchase, (b) visit, and (c) invest in a foreign country.

H2a: Country cognitions have a mediating influence on the relationship between consumer cosmopolitanism and consumers' intentions to (a) purchase, (b) visit, and (c) invest in a foreign country.

H2b: Country affect has a mediating influence on the relationship between consumer cosmopolitanism and consumers' intentions to (a) purchase, (b) visit, and (c) invest in a foreign country.

\subsection{The Moderating Effect of Materialism, Consumer Ethnocentrism (CET), Country Product Familiarity and Visits to a Country}

\subsubsection{The Moderating Effect of Materialism}

Materialism is a complex and multi-dimensional concept that has been used to compare cultures, societies or even examine institutions. Another important venue of research concerns the analysis of individual differences about materialism and its interactions with consumption behaviour, since it allows the identification of individual's elements that contribute to materialism at a cultural level and, at the same time, enables companies' managers to improve marketing activities regarding its products or services (Richins \& Dawson, 1992). Recent research conceptualises materialism in terms of the symbolic motives that underlie behaviour and is defined as follows: "Materialism is the 
extent to which individuals attempt to engage in the construction and maintenance of the self through the acquisition and use of products, services, experiences, or relationships that are perceived to provide desirable symbolic value" (Shrum, Wong, Arif, Chugani, Gunz, Lowrey, \& Sundie, 2013, p. 1180).

Before analysing the measurement of materialism it is important to highlight some of Richins and Dawson (1990) concerns underlying the development of a new measure of the concept, such as the importance of preserve a definition of materialism that ensures its neutral value, avoiding any kind of normative influence of its authors, as well as the critical aspect of a measure of materialism that excels cultures and economic systems. In the present study, materialism is defined as "a value that guides people's choices and conduct in a variety of situations, including, but not limited to, consumption arenas" (Richins \& Dawson, 1992, p. 307). The authors developed a scale to measure materialism among consumers, based on the following notions: (1) acquisition centrality - possessions and their acquisitions assume a major role in individuals' daily lives, (2) acquisition as the pursuit of happiness - materialistic individual's pursuit happiness through the acquisition of goods rather than personal relationships or experiences, and (3) possession-defined success - materialists measure success through their capacity of projecting a desired image and judge their own and other's successes by the quantity and quality of acquired goods. Hence, the following hypotheses are proposed:

H3: Materialism moderates the path between country $i$ mage and consumers' intentions to (a) purchase, (b) vis it, and (c) invest in a foreign country.

H3a: Materialism moderates the path between country c ognitions and consumers' intentions to (a) purchase, (b) visit, and (c) invest in a foreign country.

H3b: Materialism the path between country affect and consumers' intentions to (a) purchase, (b) visit, and (c) invest in a foreign country.

\subsubsection{The Moderating Effect of Consumer Ethnocentrism}

The preference for domestic products instead of foreign ones, has been a subject of great interest in consumer behaviour, described several times as prejudice against imports, domestic country bias, (e.g., Balabanis \& Diamantopoulos, 2004; Wang \& Chen, 2004; Watson \& Wright, 2000), or consumer ethnocentrism. These terms were originated from the general concept of ethnocentrism (Sharma, Shimp, \& Shin, 1995). Piron (2002, p. 197) also points out that the concept of consumer ethnocentrism helps to understand why certain consumers prefer domestic products and others seems to accept without discrimination domestic and imported ones.

Shimp and Sharma (1987, p. 280) describe consumer ethnocentrism in functional terms as giving to the individual "a sense of identity, feelings of belongingness, and, most important an understanding of what purchase behaviour is acceptable or unacceptable to the ingroup" (p. 280), employing the CET concept as a specific domain for the study of consumer behaviour with marketing implications (Sharma et al., 1995). The authors developed an instrument nominated the CETSCALE, to measure consumers' ethnocentric tendencies in order to capture the predisposition toward foreign products. One of the most important consequences of CET is related to consumer buying behaviour, more specifically, the purchase of or willingness to buy domestic versus foreign products. There are several empirical evidences that support a positive relationship between consumer ethnocentrism and purchase intentions of domestic products over foreign ones (Han, 1988; Sharma et al., 1995; Suh \& Kwon, 2002; ZarkadaFraser \& Fraser, 2002).

However, recent research recognises that a restricted focus on consumer ethnocentrism "is, at best, likely to render an incomplete picture of local bias-induced consumer behaviour" (Josiassen, 2011, p. 125) and it is important to consider a broader range of consumers' traits in what respects their behaviour on buying domestic and foreign products (Zeugner-Roth, Žabkar, \& Diamantopoulos, 2015). Though numerous studies have demonstrated a negative association between ethnocentrism and cosmopolitanism (Cannon \& Yaprak, 2002; Sharma et al., 1995), there is also evidence of the contrary, an absence of a significant relationship between them when evaluating cultural openness (Javalgi, Khare, Gross, \& Scherer, 2005; Vida \& Reardon, 2008). Therefore, the following hypotheses are proposed:

H4: CET moderates the path between country image and consumers' intentions to (a) purchase, (b) visit, and (c) invest in a foreign country.

H4a: Consumer ethnocentrism moderates the path between country cognitions and consumers' intentions to (a) purchase, (b) visit, and (c) invest in a foreign country.

H4b: Consumer ethnocentrism moderates the path between country affect and consumers' intentions to (a) purchase, (b) visit, and (c) invest in a foreign country.

\subsubsection{The Moderating Effect of Product Familiarity and Visits to the Country}

Many studies have been published concerning the importance of product and brand familiarity in consumer behaviour (Alba \& Hutchinson, 1987; Ballantyne, Warren, \& Nobbs, 2006; Kent \& Allen, 1994). According to Josiassen, Lukas, and Whitwell (2008, p. 424) product familiarity refers to "how familiar a consumer is with a given product category" and familiarity is characterised as the number of product-related experiences that have been accumulated by the consumer" (Alba \& Hutchinson, 1987, p. 
411). There are competing views concerning the role of familiarity as a moderator of the use of $\mathrm{COO}$ (as an extrinsic cue, in the evaluation and purchase of a product or product class), that might be explained by the options and assumptions made by the researcher. Initially and in agreement with the literature review, $\mathrm{COO}$ was described acting has a halo effect, allowing consumers to evaluate a product even if they were unfamiliar with (Bilkey \& Nes, 1982).

Usunier and Cestre (2007) also supported this perspective and referred that in one hand, when consumers are not familiar with a product category, the influence of COO is more likely to be strong (Eroglu \& Machleit, 1989; Maheswaran, 1994), as soon as consumers acquire greater knowledge and familiarity with a certain product category the use of $\mathrm{COO}$ tend to diminish. On the other hand, there are authors that contest this position and advocate a positive relation between the use of $\mathrm{COO}$ as an extrinsic cue and the level of product knowledge and familiarity (Johansson, 1989; Johansson, Douglas, \& Nonaka, 1985; Johansson \& Nebenzahl, 1986), being in accordance with the findings of recent research on brands showing that brand familiarity is positively related to the use of $\mathrm{COO}$ as a cue (Schaefer, 1997). For example, Johansson (1989) suggests that consumers use $\mathrm{COO}$ to summarize the evaluation of a product that they are familiar with, in order to simplify their decision-making process and save cognitive effort, mostly in cases when the decision process has to be made within a short time.

Despite the moderating role of product familiarity being consider under the halo assumption or the summary assumption, the main findings of the investigation carried out by Josiassen et al. (2008, p. 430), showed that COO image is especially important when consumers evaluate products that they are unfamiliar with. The following hypotheses have been formulated:

H5: Consumer product familiarity moderates the path between country image and consumers' intentions to (a) purchase, (b) visit, and (c) invest in a foreign country.

H5a: Consumer product familiarity moderates the path between country cognitions and consumers' intentions to (a) purchase, (b) visit, and (c) invest in a foreign country.

H5b: Consumer product familiarity the path between country affect and consumers' intentions to (a) purchase, (b) visit, and (c) invest in a foreign country.

H6: Consumer visits to a country moderates the path between country image and consumers' intentions to (a) purchase, (b) visit, and (c) invest in a foreign country.

H6a: Consumer visits to a country moderates the path between country cognitions and consumers' intentions to (a) purchase, (b) visit, and (c) invest in a foreign country.

H6b: Consumer visits to a country moderates the path between country affect and consumers' intentions to (a) purchase, (b) visit, and (c) invest in a foreign country.

\subsection{Conceptual Model}

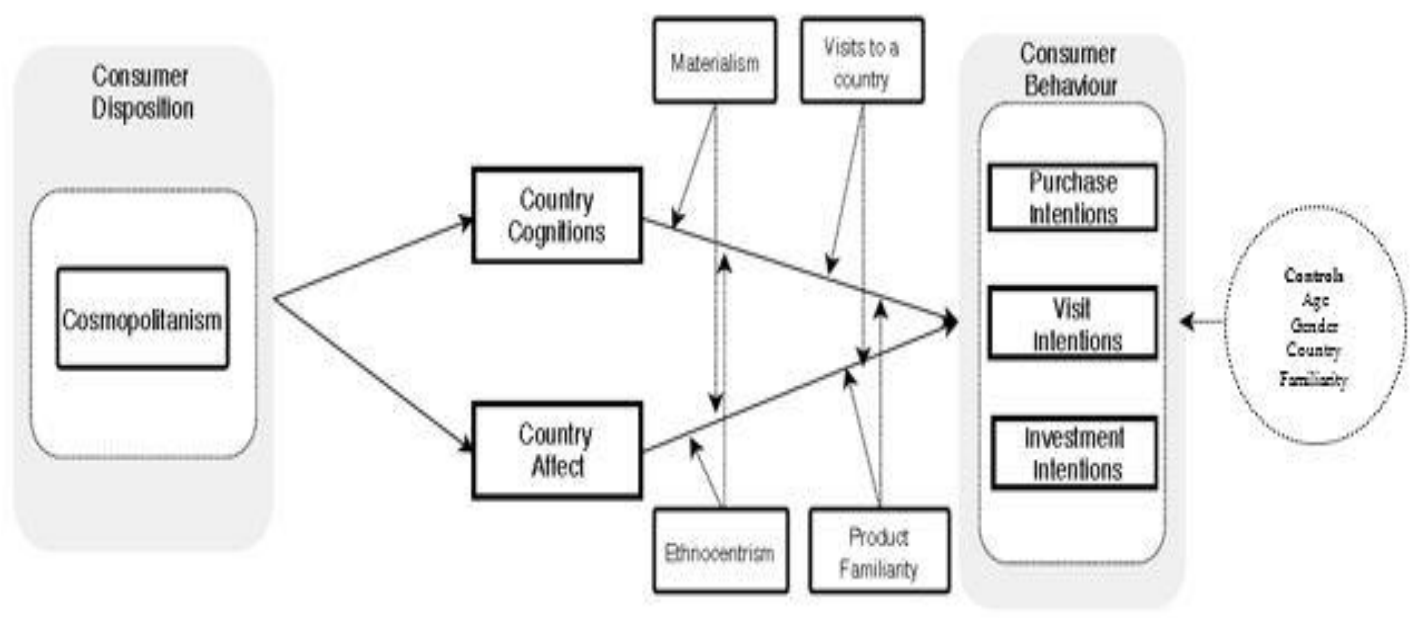

Figure 1: Displays a conceptual model of this research 


\section{Methodology}

\subsection{Instruments and Measurements}

To measure the level of consumer cosmopolitanism the C-COSMO scale from Riefler et al. (2012) has been adopted. The twelve items from C-COSMO scale were rated on a seven-point Likert format $(1=$ strongly disagree; $7=$ strongly agree). Evidence of internal consistency for the twelve-item C-COSMO in the present study is provided by estimates of Cronbach's $\alpha(\alpha=.864)$ which value exceeds the suggested .70 level (Hair, Black, Babin, \& Anderson, 2010), and for the three subscales the following estimates of Cronbach's $\alpha$ were obtained: open-mindedness $(\alpha=.876)$, diversity appreciation $(\alpha=.810)$, and consumption transcending border $(\alpha=.788)$.

Country cognitions were measured with six items adapted from Parameswaran and Pisharodi (1994), Papadopoulos, Marshall, and Heslop (1988) and Martin and Eroglu (1993), being extensively used in previous research (Laroche et al., 2005; Li, Fu, \& Murray, 1998; Roth \& Diamantopoulos, 2009). Two more item were added, namely "The Portuguese governmental institutions are able to provide an adequate service" and "The Portuguese governmental institutions make an effective use of resources", to evaluate the country cognition dimension. The eight items were rated on a seven-point Likert format $(1=$ strongly disagree; $7=$ strongly agree), and results showed evidence of internal consistency for the eight-item is provided by estimates of Cronbach's $\alpha(\alpha=.844)$.

Country affect was measured with five items using semantic differential scale, adopted from previous research (Häubl, 1996; Heslop, Papadopoulos, Dowdles, Wall, \& Compeau, 2004; Papadopoulos \& Heslop, 1993; Parameswaran \& Pisharodi, 1994), and the evidence of internal consistency for the five-item is provided by estimates of Cronbach's $\alpha(\alpha=.952)$.

To measure consumer ethnocentrism, the reduced sixitem version of CETSCALE (Shimp \& Sharma, 1987) has been used, which is consistent with the findings of the study carried out by Klein, Ettenson, and Krishnan (2006). This study reveals a consistent pattern of support for the six-item CETSCALE, with international applicability in both developed and developing economies, and evidence of internal consistency for the six-item CETSCALE provided by estimates of Cronbach's $\alpha(\alpha=.838)$, which value is similar to the Cronbach's $\alpha(\alpha=.820)$ of Klein et al. No Reference (2006). The six items were rated on a seven-point Likert format ( $1=$ strongly disagree; $7=$ strongly agree $)$.

To measure the level of materialism, a short version of the material values scale (MVS) developed by Richins (2004) was used. The nine-item version of the MVS contains three subscales designed to evaluate the success, centrality and happiness domains, and evidence of internal consistency for the nine-item short version of MVS was provided by estimates of Cronbach's $\alpha(\alpha=.852)$ and for the three subscales the following estimates of Cronbach's $\alpha$ were obtained: success $(\alpha=.796)$, centrality $(\alpha=.668)$, and happiness $(\alpha=.846)$. A seven-point Likert scale response format was used to evaluate the three dimensions of the MVS.

To assess product familiarity respondents were asked to rate how familiar they were with Portuguese products, on a seven-point Likert scale response format. This scale was adopted from Jo, Nakamoto, and Nelson (2003).

To assess purchase intentions, the three items of product evaluation from Laroche, Papadopoulos, Heslop, and Mourali (2005) have been used in a three-point semantic differential scale items, and evidence of internal consistency for the three items of product evaluation in the present study was provided by estimates of Cronbach's $\alpha(\alpha=.860)$. To measure the visit intentions, three items from the scale of Um and Crompton (1990) have been used on a seven-point Likert scale ranging from 1 - Strongly disagree, to 7 Strongly agree. Evidence of internal consistency for the three items of visit intentions in the present study was provided by estimates of Cronbach's $\alpha(\alpha=.822)$. Lastly, to assess investment intentions respondents were asked "I would invest in Portuguese projects if I could afford", on a seven-point Likert scale response format.

\subsection{Data Collection and Sample Description}

Data were collected between October and December 2016, through an online survey, using a convenience sample. In total 487 completed questionnaires were recorded and after the analysis and removal of possible outliers (evaluated by the square distance of Mahalanobis (D2)) the final sample comprised 457 consumers (Hair et al., 2010).

Regarding the demographic and socio-economic profile of the sample, $59 \%$ of the participants were female, and the average age was 27 years old (ranging between 18 and 69 years old). Return responses were received from fifty-seven nationalities and the most representative were German $(\mathrm{N}=$ 135), Spanish $(\mathrm{N}=34)$, Italian $(\mathrm{N}=42)$ and Brazil $(\mathrm{N}=57)$. Forty-seven percent of the respondents have a total household income (year) less than $20.000 €$ and $26.5 \%$ between $20.000 €$ and $80.000 €$. Seventy-five percent of the participants were students and $25 \%$ were employees.

\section{Empirical Results and Discussion}

The Statistical Package for Social Sciences (SPSS 23.0) was used to generate descriptive and inferential statistics, and the Analysis of Moments Structure (AMOS 23.0) software for conducting the structural equation modeling (SEM). The structural equation modeling was used to determine whether there is empirical support for the proposed factor structure and the causal relationship between variables of the measured model and the research hypotheses were tested. 
The measurement model achieved acceptable values of the goodness of fit indices $(\mathrm{CFI}=.933$, GFI $=.858$, TLI $=.927$ and RMSEA $=.045)$, resulting in an acceptable adjustment (Hair et al., 2010). Convergent validity was evidenced by the significant standardized loadings (average loading size was .77). Although the AVE is less than .50 for country cognitions and consumer ethnocentrism, composite reliability is higher than .60 , and the convergent validity of the constructs is still adequate (see Table 1). Discriminant validity was further investigated analysing if the square root of average variance extracted is greater than the construct correlation between any two constructs (Fornell \& Larcker, 1981). This comparison provided evidence for good discriminant validity of the seven constructs.

Table 1: Composite reliability (CR), the average variance extracted (AVE), and inter-construct correlations

\begin{tabular}{|c|c|c|c|c|c|c|c|c|c|}
\hline & CR & AVE & 1 & 2 & 3 & 4 & 5 & 6 & 7 \\
\hline 1. Cosmopolitanism & .785 & .553 & .744 & & & & & & \\
\hline 2. Country Cognitions & .840 & .402 & .251 & .634 & & & & & \\
\hline 3. Country Affect & .955 & .810 & .382 & .544 & .900 & & & & \\
\hline 5. Visit Intentions & .855 & .665 & .408 & .463 & .656 & .466 & .815 & & \\
\hline 6. Consumer Ethnocentrism & .836 & .460 & -.276 & .044 & -.034 & .026 & -.105 & 679 & \\
\hline 7. Materialism & .887 & .724 & -.037 & -.037 & -.124 & -.128 & -.034 & .082 & .851 \\
\hline
\end{tabular}

The results pertaining to the individual hypotheses are detailed below:

Hypothesis 1: results showed that cosmopolitanism has a significant and positive influence on consumers' purchasing $(\beta=.288, p<.001)$, visiting $(\beta=.433, p<.001)$, and investing $(\beta=.173, p<.001)$ intentions, thus supporting hypotheses $1 \mathrm{a}, 1 \mathrm{~b}$ and $1 \mathrm{c}$.

Hypothesis 2: concerning the mediating role of country cognitions and country affect on the relation between consumer cosmopolitanism and consumer's purchasing, visiting, and investing intentions towards a foreign country, a mediation analysis was conducted using maximum likelihood estimation. Prior to the mediation analysis the Baron and Kenny (1986) conditions for mediation were checked. All the paths were significant at a $p<.001$ level. Additionally, a mediation analysis with bootstrapping (based on 5000 samples) was conducted yielding 95\% biascorrected confidence intervals for the relative indirect effects (see Table 2).

These results show that country cognitions (CC) and country affect (CA) have a positive mediating effect on the relationship between consumer cosmopolitanism and consumers' purchase, visit and investing intentions supporting $\mathrm{H} 2 \mathrm{a}$ and $\mathrm{H} 2 \mathrm{~b}$. According to Hayes (2009) simulation research has proved that bootstrapping is one of the more valid and powerful methods for testing intervening variable effects. After preforming the bootstrapping analysis, results showed a significant, indirect effect from cosmopolitanism to purchase, visit and investment intentions through country cognitions, thus supporting H2aa, $\mathrm{H} 2 \mathrm{ab}$ and $\mathrm{H} 2 \mathrm{ac}$. Results also showed a significant, indirect effect from cosmopolitanism to purchase, visit and investment intentions through country affect, thus supporting $\mathrm{H} 2 \mathrm{ba}, \mathrm{H} 2 \mathrm{bb}$ and $\mathrm{H} 2 \mathrm{bc}$.

To test moderation multi group SEM has been performed (Hair et al., 2010), where the moderator or grouping factor is defined and the different group values are assigned. To test the categorical moderation hypotheses, we produced the critical ratios for the differences in regression weights between groups of consumer materialism (low, high), CET (low, high), consumer product familiarity (low, high), and consumer visits to a country $(1=$ No visits, $2=$ One or more visits). From these critical ratios, we calculated $p$-values to determine the significance of the difference.

Hypothesis 3: the analysis of the critical ratios for differences between individual parameters in the free model show that materialism moderates the path between $\mathrm{CC}$ and VI, for the group of low materialism consumers $(\beta=.247 ; p$ $<.05)$, partially supporting $\mathrm{H} 3 \mathrm{a}$. This means that for individuals that show low levels of materialism, CC contribute to explain VI.

Hypothesis 4: the analysis of the critical ratios for differences between individual parameters in the free model show that ethnocentrism moderates the path between $\mathrm{CC}$ and VI, for the group with high ethnocentrism $(\beta=.266 ; p$ $<.001)$, partially supporting H4a. This means that for individuals that show high levels of ethnocentrism, CC contribute to explain visit intentions. 
Table 2: Mediation analysis $(\mathrm{N}=457)$

\begin{tabular}{|c|c|c|c|}
\hline $\begin{array}{l}\text { Independent variable, mediators, and } \\
\text { dependent variables }\end{array}$ & Direct without mediator & Direct with mediator & $\begin{array}{l}\text { Bootstrapping } \\
\text { Standardised } \\
\text { Indirect effects }\end{array}$ \\
\hline $\mathrm{CCOSMO} \rightarrow \mathrm{CC} \rightarrow \mathrm{PI}$ & $.283^{* *}$ & $.105^{\star}$ & $.064^{\star *}$ \\
\hline $\mathrm{CcOSMO} \rightarrow \mathrm{CA} \rightarrow \mathrm{PI}$ & & $.103^{\star}$ & $.191^{* *}$ \\
\hline $\mathrm{CcOSMO} \rightarrow \mathrm{CC}+\mathrm{CA} \rightarrow \mathrm{PI}$ & & $102^{*}$ & $.249^{* *}$ \\
\hline $\mathrm{CCOSMO} \rightarrow \mathrm{CC} \rightarrow \mathrm{VI}$ & $.421^{* *}$ & $.223^{\star *}$ & $.054^{\star *}$ \\
\hline $\mathrm{CCOSMO} \rightarrow \mathrm{CA} \rightarrow \mathrm{VI}$ & & $.213^{\star *}$ & $.244^{* *}$ \\
\hline $\mathrm{CcosMO} \rightarrow \mathrm{CC}+\mathrm{CA} \rightarrow \mathrm{VI}$ & & $.209^{* *}$ & $.288^{* *}$ \\
\hline $\mathrm{ccosMO} \rightarrow \mathrm{CC} \rightarrow \mathrm{II}$ & $.171^{\star *}$ & .032 & $.109^{\star *}$ \\
\hline $\mathrm{CcOSMO} \rightarrow \mathrm{CA} \rightarrow \mathrm{II}$ & & .032 & $.083^{*}$ \\
\hline $\mathrm{CcOSMO} \rightarrow \mathrm{CC}+\mathrm{CA} \rightarrow \mathrm{II}$ & & .032 & $.190^{\star *}$ \\
\hline \multicolumn{4}{|c|}{ Direct effect } \\
\hline $\mathrm{ccosmO} \rightarrow \mathrm{CC}$ & & $.298^{* *}$ & \\
\hline $\mathrm{ccOSMO} \rightarrow \mathrm{CA}$ & & $.434^{* *}$ & \\
\hline $\mathrm{CC} \rightarrow \mathrm{PI}$ & & $.207^{\star *}$ & \\
\hline $\mathrm{CC} \rightarrow \mathrm{VI}$ & & $.169^{\star *}$ & \\
\hline $\mathrm{CC} \rightarrow \mathrm{II}$ & & $.363^{*}$ & \\
\hline $\mathrm{CA} \rightarrow \mathrm{PI}$ & & $.431^{* *}$ & \\
\hline $\mathrm{CA} \rightarrow \mathrm{VI}$ & & $.548^{\star \star}$ & \\
\hline $\mathrm{CA} \rightarrow \mathrm{II}$ & & $.188^{\star *}$ & \\
\hline
\end{tabular}

Note: * effects are significant at $p<.05 ;{ }^{* *}$ effects are significant at $p<.001$; Indirect effects are based on 5.000 bootstrapping samples and control for gender, age, country familiarity and visits; Consumer Cosmopolitanism (CCOSMO); Country Cognitions (CC); Country Affect (CA); Purchase Intentions (PI); Visit Intentions (VI); Investment Intentions (II).

Hypothesis 5: the analysis of the critical ratios for differences between individual parameters in the free model show that consumer product familiarity positively moderates the path between $\mathrm{CC}$ and VI, for the group with high product familiarity $(\beta=.285 ; p<.001)$, partially supporting H5a.This means that $\mathrm{CC}$ are important to explain visit intentions for individuals that show high levels of product familiarity.

Hypothesis 6: the analysis of the critical ratios for differences between individual parameters in the free model show that consumer visits to a country positively moderates the path between $\mathrm{CC}$ and VI, for the group that visited the country $(\beta=.276 ; p<.001)$, partially supporting H6a. Although the influence of CA on VI is significant and positive for consumers who have visited the country $(\beta$ $=.423 ; \mathrm{p}<.001)$, it is stronger for those who did not visited the country $(\beta=.669 ; \mathrm{p}<.001)$ partially supporting H6b. This means that both country cognitions and country affect are important to explain visit intentions.

The $\mathrm{R}^{2}$ indicates that $35 \%, 52.5 \%$, and $21.3 \%$ of the total variation of the purchase intentions towards Portuguese products, visit and investment intentions, respectively, may be explained by the relationship between consumer cosmopolitanism and consumers' purchasing, visiting and investing intentions, considering the mediating effect of country image dimensions, controlled for the influence of age, gender and country familiarity.

\section{Conclusions}

The purpose of this study was to analyse the mediating effect of Country Image on the relationship between consumer cosmopolitanism and consumers' purchase, visit and investment intentions, and how the effect of the moderating variables consumer ethnocentrism, materialism, country product familiarity and visits to a country, influence the relationship between CI dimensions and consumers' behavioural intentions towards a foreign country.

This study is in accordance with the study carried out by Bartsch, Riefler, and Diamantopoulos (2016) which suggest that it is important to analyse the effects of positive consumer dispositions on cognitive, affective, and 
behavioural variables relating to global and foreign products and brands. One of the reasons concerns the importance of considering the role of cosmopolitanism as a potential segmentation variable in international markets. The results of this study show that cosmopolitanism has a significant and positive effect on foreign consumers' intentions to buy, visit and invest in a foreign country. Moreover, this study also shows that the cognitive and the affective image mediate this relationship. This means that despite the positive influence of cosmopolitanism on consumers' intentional behaviour, the image that foreign consumers hold about a selected country, help to better explain their intentions to buy or invest in the country, as well as to think of Portugal as a tourism destination. Moreover, this study also contributes to overcoming the lack of studies employing Portugal as a country of origin (Usunier, 2006) providing evidence to the assessment of the external generalization of previous findings.

From a managerial standpoint, due to the growing interdependence of the world's economies, cultures, and populations, companies' managers should pay particular attention on how to effectively address consumers, in order to make their products and services appealing, at a domestic and international level. The results of this study indicate the importance of regarding cosmopolitanism as a positive consumer disposition segmentation variable, that influences the intentions to buy, visit or invest in a selected country. These results might also help international managers and policymakers to develop specific activities enhancing the positive country image associated with Portugal. Moreover, these professionals should consider the difference of the influence that country cognitions and country affect have on consumers' intentions to purchase, visit or invest in the country.

Concerning the influence of the moderating effects on the relationship between country image and consumer intentional behaviour, it is important to analyse the effect of materialism, ethnocentrism, product familiarity and if the consumer has visited (or not) the country. The influence of these concepts has been significant on the relationship between country cognitions and visit intentions, and its analysis is of particular interest for policymakers and destination managers. Despite the direction of the influence (high or low), companies and destination managers and policymakers should analyse this effect on the relationship between country cognitions and visit intentions. Thenceforth, activities should be developed to promote country beliefs for low materialistic and high ethnocentric consumers. This means that for consumers that show a low level of materialism, the cognitions (beliefs) associated with Portugal are important to explain their intentions to visit the country. The same reasoning also applies to high ethnocentric consumers, which means that cognitions (beliefs) associated with Portugal contribute to justify their intentions to visit the country.

Results also show that for the group with high product familiarity country cognitions (beliefs) help to explain visit intentions. Lastly, it is interesting to analyse the moderator effect of consumer visits to the country on the relationship between country cognitions and visits intentions. On the one hand, country cognitions are important for individuals who have visited the country one or more times. However, for consumers who have not visited the country, country affect contributes to explain their intentions to visit Portugal.

\section{Limitations and Suggestions for Future Research}

This study aimed to analyse the mediating effect of country image dimensions on the relationship between consumer cosmopolitanism and consumers' purchase, visit and investment intentions, considering the moderating effects of consumer ethnocentrism, materialism, product familiarity, and visits to a country. It presents some limitations namely, it only evaluates the perceptions of consumers from developed countries and calls into question if the results might differ for consumers from developing or less developed countries. Furthermore, it only evaluates a selected positive consumer disposition, namely consumer cosmopolitanism.

Future studies might analyse the simultaneous influence of positive and negative consumer's dispositions towards consumer behaviour considering further moderating effects such as product category, level of economic development and/or perceived brand globalness and perceived brand local iconness. Another avenue for future research might be to analyse the influence of positive (e.g., cosmopolitanism) and negative consumers' dispositions (e.g., ethnocentrism) towards foreign countries, considering cultural differences, such as the cultural paradigm of Hofstede (Hofstede, Hofstede, \& Minkov, 2010) or the cultural dimensions suggested by Schwartz (Schwartz, Cieciuch, Vecchione, Davidov, Fischer, Beierlein, \& Konty, 2012), and analyse its influence on consumer buying behaviour.

\section{Reference}

Alba, J. W., \& Hutchinson, J. W. (1987). Dimensions of consumer expertise. Journal of Consumer Research, 13(4), 411-454.

Alden, D. L., Steenkamp, J.-B. E. M., \& Batra, R. (2006). Consumer attitudes toward marketplace globalization: Structure, antecedents and consequences. International Journal of Research in Marketing, 23, 227-239.

Allred, A., Chakraborty, G., \& Miller, S. J. (2000). Measuring images of developing countries: A scale development study. Journal of Euromarketing, 8(3), 2949.

Anderson, A. (1998). Cosmopolitanism, universalism, and the divided legacies of modernity. In P. Cheah \& B. Robbins (Eds), Cosmopolitics thinking and feeling 
beyond the nation (pp. 265-289). Minneapolis, MN: University of Minnesota Press.

Askegaard, S., \& Ger, G. (1998). Product-country images: Towards a contextualized approach. European Advances in Consumer Research, 3, 50-58.

Balabanis, G., \& Diamantopoulos, A. (2004). Domestic country bias, country-of-origin effects, and consumer ethnocentrism: A multidimensional unfolding approach. Journal of the Academy of Marketing Science, 32(1), 8095.

Ballantyne, R., Warren, A., \& Nobbs, K. (2006). The evolution of brand choice. Journal of Brand Management, 13(4/5), 339-352.

Barich, H., \& Kotler, P. (1991). A framework for marketing image management. Sloan Management Review, 32(Winter), 94-104.

Baron, R. M., \& Kenny, D. A. (1986). The moderatormediator variable distinction in social psychological research: Conceptual, strategic, and statistical considerations. Journal of Personality and Social Psychology, 51(6), 1173-1182.

Bartsch, F., Riefler, P., \& Diamantopoulos, A. (2016). A taxonomy and review of positive consumer dispositions toward foreign countries and globalization. Journal of International Marketing, 24(1), 82-110.

Bilkey, W. J., \& Nes, E. (1982). Country-of-origin effects on product evaluations. Journal of International Business Studies, 13(1), 89-99.

Caldwell, M., Blackwell, K., \& Tulloch, K. (2006). Cosmopolitanism as a consumer orientation: Replicating and extending prior research. Qualitative Market Research: An International Journal, 9(2), 126-139.

Cannon, H. M., \& Yaprak, A. (2002). Will the real-world citizen please stand up! The many faces of cosmopolitan consumer behavior. Journal of International Marketing, 10(4), 30-52.

Carneiro, J., \& Faria, F. (2016). Quest for purposefully designed conceptualization of the country-of-origin image construct. Journal of Business Research, 69(10), 4411-4420.

Cleveland, M., \& Laroche, M. (2007). Acculturaton to the global consumer culture: Scale development and research paradigm. Journal of Business Research, 60, 249-259.

Cleveland, M., Laroche, M., Takahashi, I., \& Erdoğan, S. (2014). Cross-linguistic validation of a unidimensional scale for cosmopolitanism. Journal of Business Research, 67, 268-277.

Eroglu, S. A., \& Machleit, K. A. (1989). Effects of individual and product-specific variables on utilising country of origin as a product quality cue. International Marketing Review, 6(6), 27-41.

Fetscherin, M. (2010). The determinants and measurement of a country brand: The country brand strength index. International Marketing Review, 27(4), 466-479.
Fishbein, M., \& Ajzen, I. (1975). Belief, attitude, intention and behavior: An introduction to theory and research. Reading, MA: Addison-Wesley Publishing Company.

Fornell, C., \& Larcker, D. F. (1981). Evaluating Structural Equation Models with unobservable variables and measurement error. Journal of Marketing Research (JMR), 18(1), 39-50.

Hair, J. F., Black, B., Babin, B., \& Anderson, R. E. (2010). Multivariate data analysis. Upper Saddle River, NJ: Prentice Hall.

Han, C. M. (1988). The role of consumer patriotism in the choice of domestic versus foreign products. Journal of Advertising Research, 28(3), 25.

Hankinson, G. (2001). Location branding: A study of the branding practices of 12 English cities. Journal of Brand Management, 9(2), 127-142.

Hannerz, U. (1990). Cosmopolitans and locals in world culture. Theory, Culture \& Society, 7(2), 237-251.

Häubl, G. (1996). A cross-national investigation of the effects of country of origin and brand name on the evaluation of a new car. International Marketing Review, 13(5), 76-97.

Hayes, A. F. (2009). Beyond Baron and Kenny: Statistical mediation analysis in the new millennium. Communication Monographs, 76(4), 408-420.

Heslop, L. A., Papadopoulos, N., Dowdles, M., Wall, M., \& Compeau, D. (2004). Who controls the purse strings: A study of consumers' and retail buyers' reactions in an America's FTA environment. Journal of Business Research, 57, 1177-1188.

Hofstede, G., Hofstede, G. J., \& Minkov, M. (2010). Cultures and organizations: Software of the mind, revised and expanded (3rd ed.). New York, NY: McGraw-Hill.

Javalgi, R. G., Khare, V. P., Gross, A. C., \& Scherer, R. F. (2005). An application of the consumer ethnocentrism model to French consumers. International Business Review, 14(3), 325-344.

Jo, M.-S., Nakamoto, K., \& Nelson, J. E. (2003). The shielding effects of brand image against lower quality countries-of-origin in global manufacturing. Journal of Business Research, 56(8), 637-646.

Johansson, J. K. (1989). Determinants and effects of the use of "Made In" labels. International Marketing Review, $6(1), 47-72$.

Johansson, J. K., Douglas, S. P., \& Nonaka, I. (1985). Assessing the impact of country of origin on product evaluations: A new methodological perspective. Journal of Marketing Research, 22(4), 388-396.

Johansson, J. K., \& Nebenzahl, I. D. (1986). Multinational production: Effect on brand value. Journal of International Business Studies, 17(3), 101-126.

Josiassen, A., Lukas, B. A., \& Whitwell, G. J. (2008). Country-of-origin contingencies: Competing perspectives on product familiarity and product involvement. International Marketing Review, 25(4), 423-440. 
Kent, R. J., \& Allen, C. T. (1994). Competitive interference effects in consumer memory for advertising: The role of brand familiarity. Journal of Marketing, 58(3), 97-105.

Killingbeck, A. J., \& Trueman, M. M. (2002). Redrawing the perceptual map of a city (Working paper No 02/08). Bradford, England: School of Management, University of Bradford.

Kleppe, I. A., Iversen, N. M., \& Stensaker, I. G. (2002). Country images in marketing strategies: Conceptual issues and an empirical Asian illustration. Journal of Brand Management, 10(1), 61-74.

Kotler, P., \& Gertner, D. (2002). Country as brand, product, and beyond: A place marketing and brand management perspective. Journal of Brand Management, 9(4/5), 249261.

Laroche, M., Papadopoulos, N., Heslop, L. A., \& Mourali, M. (2005). The influence of country image structure on consumer evaluations of foreign products. International Marketing Review, 22(1), 96-115.

Li, Z. G., Fu, S., \& Murray, L. W. (1998). Country and product images: The perceptions of consumers in the People's Republic of China. Journal of International Consumer Marketing, 10(1-2), 115-139.

Maheswaran, D. (1994). Country of origin as a stereotype: Effects of consumer expertise and attribute strength on product evaluations. Journal of Consumer Research, 21(2), 354-365.

Martin, I. M., \& Eroglu, S. (1993). Measuring a multidimensional construct: Country image. Journal of Business Research, 28(3), 191-210.

Min Han, C. (1989). Country image: Halo or summary construct? Journal of Marketing Research, 26(2), 222229.

Nebenzahl, I. D., Jaffe, E. D., \& Usunier, J.-C. (2003). Personifying country of origin research. Management International Review, 43(4), 383-406.

Papadopoulos, N. (1993). What product and country images are and are not. In L. A. H. E. N. Papadopoulos (Ed.), Product-country images: Impact and role in international marketing (pp. 1-38). New York, NY: Haworth Press.

Papadopoulos, N., \& Heslop, L. A. (1993). Product-country images: Impact and role in international marketing. Binghamton, NY: International Business Press.

Papadopoulos, N., Marshall, J. J., \& Heslop, L. A. (1988). Strategic implications of product and country images: A modeling approach. Paper presented at the Marketing Productivity, European Society for Opinion and Marketing Research, Lisbon.

Parameswaran, R., \& Pisharodi, R. M. (1994). Facets of country of origin image: An empirical assessment. Journal of Advertising, 23(1), 43-56.

Piron, F. (2002). International outshopping and ethnocentrism. European Journal of Marketing, 36(1/2), 189-210.
Richins, M. L. (2004). The material values scale: Measurement properties and development of a short form. Journal of Consumer Research, 31(1), 209-219.

Richins, M. L., \& Dawson, S. (1990). Measuring material values: A preliminary reports of scale development. Advances in Consumer Research, 17(1), 169-175.

Richins, M. L., \& Dawson, S. (1992). A consumer values orientation for materialism and its measurement: Scale development and validation. Journal of Consumer Research, 19(3), 303-316.

Riefler, P., \& Diamantopoulos, A. (2009). Consumer cosmopolitanism: Review and replication of the CYMYC scale. Journal of Business Research, 62(4), 407-419.

Riefler, P., Diamantopoulos, A., \& Siguaw, J. A. (2012). Cosmopolitan consumers as a target group for segmentation. Journal of International Business Studies, 43(3), 285-305.

Roth, K. P., \& Diamantopoulos, A. (2009). Advancing the country image construct. Journal of Business Research, 62(7), 726-740.

Saran, A., \& Kalliny, M. (2012). Cosmopolitanism: Concept and measurement. Journal of Global Marketing, 25(5), 282-291.

Schaefer, A. (1997). Consumer knowledge and country of origin effects. European Journal of Marketing, 31(1), 56-72.

Schwartz, S. H., Cieciuch, J., Vecchione, M., Davidov, E., Fischer, R., Beierlein, C., \& Konty, M. (2012). Refining the theory of basic individual values. Journal of Personality and Social Psychology, 103(4), 663-688.

Sharma, S., Shimp, T. A., \& Shin, J. (1995). Consumer ethnocentrism: A test of antecedents and moderators. Journal of the Academy of Marketing Science, (1), 26-37.

Shimp, T. A., \& Sharma, S. (1987). Consumer ethnocentrism: Construction and validation of the CETSCALE. Journal of Marketing Research (JMR), 24(3), 280-289.

Shrum, L. J., Wong, N., Arif, F., Chugani, S. K., Gunz, A., Lowrey, T. M., \& Sundie, J. (2013). Reconceptualizing materialism as identity goal pursuits: Functions, processes, and consequences. Journal of Business Research, 66(8), 1179-1185.

Suh, T., \& Kwon, I. W. G. (2002). Globalization and reluctant buyers. International Marketing Review, 19(6), 663-680.

Usunier, J.-C. (2006). Relevance in business research: The case of country-of-origin research in marketing. European Management Review, 3(1), 60-73.

Usunier, J.-C., \& Cestre, G. (2007). Product ethnicity: Revisiting the match between products and countries. Journal of International Marketing, 15(3), 32-72.

Vida, I., \& Reardon, J. (2008). Domestic consumption: rational, affective or normative choice? Journal of Consumer Marketing, 25(1), 34-44.

Wang, C. L., \& Chen, Z. X. (2004). Consumer ethnocentrism and willingness to buy domestic products 
in a developing country setting: Testing moderating effects. Journal of Consumer Marketing, 21(6), 391-400.

Watson, J. J., \& Wright, K. (2000). Consumer ethnocentrism and attitudes toward domestic and foreign products. European Journal of Marketing, 34(9/10), 1149-1166.

White, C., Kiousis, S., Buhmann, A., \& Ingenhoff, D. (2019). Epilogue: Bridging disciplinary perspectives of country image reputation, brand, and identity: Reputation, brand, and identity. In D. Ingenhoff, C. White, A. Buhmann, \& S. Kiousis (Eds.), Bridging Disciplinary Perspectives of Country Image Reputation, Brand, and Identity: Reputation, Brand, and Identity (pp. 289-300). New York, NY: Routledge.
Zarkada-Fraser, A., \& Fraser, C. (2002). Store patronage prediction for foreign-owned supermarkets. International Journal of Retail \& Distribution Management, 30(6), 282-299.

Zeugner-Roth, K. P., \& Žabkar, V. (2015). Bridging the gap between country and destination image: Assessing common facets and their predictive validity. Journal of Business Research, 68(9), 1844-1853.

Zeugner-Roth, K. P., Žabkar, V., \& Diamantopoulos, A. (2015). Consumer ethnocentrism, national identity, and consumer cosmopolitanism as drivers of consumer behavior: A Social Identity Theory Perspective. Journal of International Marketing, 23(2), 25-54. 